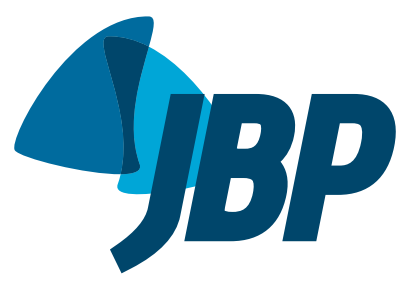

1. Programa de Pós-Graduação em Ciências Pneumológicas, Faculdade de Medicina, Universidade Federal do Rio Grande do Sul - UFRGS Porto Alegre (RS) Brasil.

2. Department of Clinical Research and Radiology, Liverpool Heart and Chest Hospital NHS Foundation Trust Liverpool, United Kingdom

3. Faculdade de Medicina, Universidade Federal do Espírito Santo, Vitória (ES) Brasil.

4. Departamento de Medicina Clínica e Saúde Pública, Universidade Federa de Ciências da Saúde de Porto Alegre Porto Alegre (RS) Brasil.

5. Programa de Pós-Graduação em Medicina e Ciências da Saúde, Faculdade de Medicina, Pontifícia Universidade Católica do Rio Grande do Sul, Porto Alegre (RS) Brasil.

a. (iD) http://orcid.org/0000-0002-6948-3982

b. (iD) http://orcid.org/0000-0002-1737-7440

c. (iD http://orcid.org/0000-0001-9284-884X

d. (iD http://orcid.org/0000-0001-7851-5125

e. (iD http://orcid.org/0000-0001-9214-1916

f. (iD) http://orcid.org/0000-0002-4822-7082

g. (iD) http://orcid.org/0000-0002-4985-6374

h. (iD http://orcid.org/0000-0001-6428-6421

i. (iD) $h t t p: / / o r c i d . o r g / 0000-0002-6294-917 X$

j. (iD http://orcid.org/0000-0001-9121-6365

k. (iD http://orcid.org/0000-0003-2896-8059

I. iD http://orcid.org/0000-0003-1345-0476

Submitted: 23 January 2018

Accepted: 22 April 2018

Study carried out at Hospital Santa Rita, Complexo Hospitalar Santa Casa de Porto Alegre, Porto Alegre (RS) Brasil.

\section{Proportional weight loss in six months as a risk factor for mortality in stage IV non- small cell lung cancer}

Guilherme Watte1,2,5,a, Claudia Helena de Abreu Nunes', ${ }^{1, b}$, Luzielio Alves Sidney-Filho ${ }^{3, c}$, Matheus Zanon ${ }^{2,4, \mathrm{~d}}$, Stephan Philip Leonhardt Altmayer ${ }^{4,5, \mathrm{e}}$, Gabriel Sartori Pacini ${ }^{4, \mathrm{f}}$, Marcelo Barros ${ }^{5,9}$, Ana Luiza Schneider Moreira ${ }^{4, h}$, Rafael José Vargas Alves ${ }^{1, i}$, Alice de Medeiros Zelmanowicz ${ }^{4, j}$, Bashir Mnene Matata ${ }^{2, k}$, Jose da Silva Moreira ${ }^{1,1}$

\section{ABSTRACT}

Objective: To evaluate different weight loss (WL) cut-off points as prognostic markers of 3-month survival after diagnosis of stage IV non-small cell lung cancer (NSCLC). Methods: This was a prospective study involving 104 patients with metastatic (stage IV) NSCLC who were admitted to a cancer treatment center in southern Brazil between January of 2014 and November of 2016. We evaluated total WL and WL per month, as well as WL and WL per month in the 6 months preceding the diagnosis. The patients were followed for 3 months after diagnosis. A Cox proportional hazards regression model and Kaplan-Meier curves were used in order to evaluate 3-month survival. Results: The median WL in the 6 months preceding the diagnosis was $6 \%$ (interquartile range, 0.0 $12.9 \%)$. Patients with WL $\geq 5 \%$ had a median survival of 78 days, compared with 85 days for those with $W L<5 \%(p=0.047)$. Survival at 3 months was $72 \%$ for the patients with $W L \geq 5 \%(p=0.047), 61 \%$ for those with $W L \geq 10 \%(p<0.001)$, and $45 \%$ for those with $W L \geq 15 \%(p<0.001)$. In the multivariate analysis, the hazard ratio for risk of death was 4.51 (95\% Cl: 1.32-15.39) for the patients with WL $\geq 5 \%, 6.34$ (95\% Cl: 2.31-17.40) for those with $W L \geq 10 \%$, and 14.17 (95\% Cl: $5.06-39.65)$ for those with $W L \geq 15 \%$. Conclusions: WL in the 6 months preceding the diagnosis of NSCLC is a relevant prognostic factor and appears to be directly proportional to the rate of survival at 3 months.

Keywords: Weight loss; Carcinoma, non-small-cell lung; Prognosis.

\section{INTRODUCTION}

Weight loss (WL) is a common complaint of patients with lung cancer and a common reason for patient referral to a specialist.(1-3) Cancer cachexia, resulting from an imbalance between energy intake and consumption, is associated with a combination of poor caloric intake and increased resting energy expenditure, probably due to a cytokine-induced systemic inflammatory response. ${ }^{(4)}$ Some studies have demonstrated that this increase in resting energy expenditure can also vary depending on the type of tumor. ${ }^{(8,9)}$ Other factors that contribute to cancer cachexia include nausea, vomiting, constipation, diarrhea, pain, altered taste perception, and depression. ${ }^{(1)}$

Despite its potential benefit for the clinical evaluation of patients with non-small cell lung cancer (NSCLC), the definition of cachexia varies significantly across studies and many WL cut-off points have been proposed in the attempt to classify the syndrome in an objective manner. ${ }^{(10-14)}$ A recent consensus suggested that WL be defined as any decrease greater than $5 \%$ in relation to the usual weight or greater than $2 \%$ in individuals with a body mass index $<20 \mathrm{~kg} / \mathrm{m}^{2}$. ${ }^{(13)}$ However, setting up a single cut-off point to classify cachexia can underestimate its real prognostic value. Different levels of cachexia severity can have various effects on the prognosis of cancer and could serve as a valuable clinical indicator.

The objective of this study was to evaluate 3-month survival in a population of patients with stage IV NSCLC. We also tested the prognostic value of different WL cut-off points. 


\section{METHODS}

\section{Study population}

This prospective cohort study was conducted at Santa Rita Hospital, an oncology referral center and part of the Santa Casa de Misericórdia de Porto Alegre Hospital Complex, in the city of Porto Alegre, located in southern Brazil. We included consecutive patients newly diagnosed with metastatic (stage IV) NSCLC and admitted to Santa Rita Hospital between January of 2014 and November of 2016. Patients were treated at the discretion of the attending physician. All patients received a nutritional consultation at admission, regularly received high-calorie meals, and were instructed to rest before meals. However, they did not receive any type of nutritional supplementation as part of the palliative care or during chemotherapy. The follow-up period was $\leq 3$ months after the diagnosis of cancer, as confirmed by reviews of medical records, hospital records, and phone calls. All diagnoses required clinical, radiological, and histological confirmation. Patients who had previously undergone antineoplastic treatment were excluded, as were those who were under 18 years of age. Survival and mortality rates were calculated from the time of the histological diagnosis until death or until the end of the third month of follow-up. Patient charts were reviewed, and tumor-node-metastasis variables were upgraded in accordance with the revised stage groupings established by the International Association for the Study of Lung Cancer. ${ }^{(15)}$ Performance status was assessed with the Eastern Cooperative Oncology Group scale. ${ }^{(16)}$ The study was approved by the local institutional review board. All participating patients gave written informed consent.

\section{WL classification}

Each patient was prospectively evaluated following the standards established in previous reports. ${ }^{(17)}$ Definitions of WL-related variables were also based on those established in other studies(10): total WL-the difference between weight at the time of diagnosis and usual weight; WL per month-total WL divided by the number of months of WL; and WL per month in 6 months-total difference between weight at the time of diagnosis and weight in the preceding 6 months. Patients were also subjectively evaluated in terms of their self-awareness of WL at the time of NSCLC diagnosis in relation to their usual weight. Different WL cut-off points ( $5 \%, 10 \%$, and $15 \%)$ were tested in order to classify cachexia and to correlate the different degrees of cachexia with the survival rates.

\section{Statistical analysis}

Continuous variables are expressed as medians and interquartile range (IQR). Univariate analyses of survival were based on the Kaplan-Meier method. ${ }^{(18)}$ Survival was calculated by Cox proportional hazards regression model in a multivariate analysis. ${ }^{(19)}$ The Wald test was used in order to calculate significance for each factor. All parameters associated with mortality $(p<0.1)$ in the univariate analysis were included in a multivariate model, in which values of $p<0.05$ were considered statistically significant. All tests were two-tailed, with the level of significance set at 0.05 . All results were analyzed with the SPSS Statistics software package, version 20.0 (IBM Corporation, Armonk, NY, USA).

\section{RESULTS}

Patient characteristics are summarized in Table 1. The median age was 63 years (IQR, 52.5-69.0 years). Of a total of 104 patients evaluated, 63 (60.6\%) were male. The most prevalent histological type of NSCLC was adenocarcinoma, which was seen in 57 (54.7\%) of the patients, followed by squamous cell carcinoma, seen in 36 (34.6\%), and mixed/undefined, seen in 11 (10.6\%). The median Eastern Cooperative Oncology Group performance status was 2 (IQR, 1-3). Most $(60.6 \%)$ of the patients underwent chemotherapy after diagnosis. Of the 104 patients, 44 (42.3\%) underwent radiation therapy and $10(9.6 \%)$ received supportive care exclusively. The 3-month mortality rate was $20.1 \%$ (95\% CI: 12.9-29.1), 21 patients dying within the first 3 months after being diagnosed with cancer. The median WL in 6 months was 6\% (IQR, 0.0-12.9\%).

Patient outcomes, stratified by WL cut-off points, are summarized in Table 2. All cut-off points for WL in 6 months were statistically associated with a poorer prognosis as assessed by mean days of survival in 3 months. Patients with $\mathrm{WL} \geq 5 \%$ had a mean survival of 78 days, compared with 85 days for those with WL $<5 \%(p=0.047)$. When the WL cut-off points of $\geq$ $10 \%$ and $\geq 15 \%$ were applied, the mean survival decreased to 73 days and 66 days, respectively ( $p<$ 0.001 for both). However, there was no statistically significant difference between the patients who were aware of their WL and those who were not in terms of the 3-month survival rate $(p=0.081)$.

Kaplan-Meier survival curves for the first 3 months after diagnosis are shown in Figure 1. We observed a direct linear trend between the proportional WL and mortality. Event-free survival at 3 months was $88 \%$ for the patients with $\mathrm{WL}<5 \%$, compared with $72 \%$ for those with WL $\geq 5 \%$ ( $p=0.047), 61 \%$ for those with $W L \geq 10 \%$ ( $p<0.001)$, and $45 \%$ for those with $W L \geq 15 \%(p<0.001)$.

The outcomes of the Cox proportional hazards regression model are summarized in Table 3. The univariate and multivariate (adjusted) analyses both demonstrated that the risk of death during the 3-month follow-up period was higher when the higher WL cut-off points were applied. The adjusted multivariate analysis showed that the risk of death increases exponentially as the cut-off points of WL increase, the hazard ratios for the $5 \%, 10 \%$, and $15 \%$ cut-off points being 4.51 (95\% CI: 1.32-15.39), 6.34 (95\% CI: 2.31-17.40), and 14.17 (95\% CI: 5.06-39.65), respectively.

\section{DISCUSSION}

In the present study, our aim was to determine the value of $\mathrm{WL}$ as a prognostic factor in patients with 
Table 1. Baseline anthropometric and clinical characteristics of the study sample.

\begin{tabular}{lc}
\multicolumn{1}{c}{ Characteristic } & $\mathbf{N}=104$ \\
Male gender, $\mathrm{n}(\%)$ & $63(60.6)$ \\
Age (years), median (IQR) & $63(52.5$ to 69.0) \\
Body weight at diagnosis (kg), median (IQR) & $63(53.0$ to 70.7$)$ \\
Patient awareness of WL, $\mathrm{n}(\%)$ & $67(64.4)$ \\
Smoking status, $\mathrm{n}(\%)$ & \\
$\quad$ Non-smoker & $18(17.3)$ \\
$\quad$ Former smoker & $51(49.0)$ \\
$\quad$ Current smoker & $35(33.7)$ \\
Total WL, median (IQR) & $-6.0 \%(-12.9 \%$ to $0 \%)$ \\
WL per month, median (IQR) & $-1.0 \%(-2.1 \%$ to $0 \%)$ \\
WL in 6 months, median (IQR) & $-6.0 \%(-12.4 \%$ to $0 \%)$ \\
WL in 6 months $\geq 5 \%, \mathrm{n}(\%)$ & $59(56.7)$ \\
WL in 6 months $\geq 10 \%, \mathrm{n}(\%)$ & $36(34.6)$ \\
WL in 6 months $\geq 15 \%, \mathrm{n}(\%)$ & $22(21.2)$ \\
ECOG PS, median (IQR) & $2(1$ to 3$)$ \\
Tumor cell type, $\mathrm{n}(\%)$ & \\
$\quad$ Adenocarcinoma & $57(54.8)$ \\
Squamous cell carcinoma & $36(34.6)$ \\
Mixed or undefined histology & $11(10.6)$ \\
Main treatment, $\mathrm{n}(\%)$ & \\
$\quad$ Chemotherapy & $63(60.6)$ \\
Supportive care only & $10(9.6)$ \\
Radiation therapy & $44(42.3)$ \\
\hline
\end{tabular}

IQR: interquartile range; WL: weight loss; and ECOG-PS: Eastern Cooperative Oncology Group performance status.

Table 2. Kaplan-Meier survival analysis, by weight loss-related variable.

\begin{tabular}{|c|c|c|c|}
\hline Variable & $\begin{array}{l}\text { Mean survival } \\
\text { Days }(95 \% \mathrm{CI})\end{array}$ & $x^{2}$ & p* \\
\hline \multicolumn{4}{|l|}{ WL, self-awareness } \\
\hline Yes & $85(80-89)$ & 3.05 & 0.080 \\
\hline No & $78(73-84)$ & & \\
\hline \multicolumn{4}{|c|}{ Proportional WL in 6 months } \\
\hline$<5 \%$ & $85(80-89)$ & 3.94 & 0.047 \\
\hline$\geq 5 \%$ & $78(72-84)$ & & \\
\hline$<10 \%$ & $85(81-89)$ & 11.58 & $<0.001$ \\
\hline$\geq 10 \%$ & $73(64-82)$ & & \\
\hline$<15 \%$ & $85(81-88)$ & 23.78 & $<0.001$ \\
\hline$\geq 15 \%$ & $66(53-78)$ & & \\
\hline
\end{tabular}

WL: weight loss. *Log-rank test.

NSCLC, as well as whether that association differs among four WL cut-off points. We have shown that greater WL translates to shorter overall survival for patients with NSCLC. We found that, among patients with advanced NSCLC, the 3-month mortality rate was almost two times higher for those with WL $\geq 15 \%$ than for those with $\mathrm{WL}<5 \%$. Our results suggest that pre-treatment WL is an important clinical parameter with relevant prognostic value in patients with advanced NSCLC.

Our findings are consistent with those of previous studies that evaluated survival and WL in populations of lung cancer patients that were more heterogeneous, including patients in different stages of the disease..$^{(1-3,10-12,20-22)}$ The prognostic significance of WL in stage IV NSCLC could be attributed to the potential link to cachexia. Defined as a multifactorial syndrome of progressive loss of skeletal muscle mass that cannot be completely reversed, cachexia has a heterogeneous clinical presentation that varies according to tumor type, site, and stage. ${ }^{(13,21)}$ Lung cancer is often accompanied by malnutrition, sarcopenia, and cachexia. Following the cancer-specific cachexia classifications, van der Meij et al. ${ }^{(23)}$ demonstrated that, at the time of diagnosis, approximately $18 \%$ and $23 \%$ of stage III NSCLC patients had cachexia or were in a state of pre-cachexia, respectively. However, the exact basis of these prognostic differences remains unknown.

Several hypotheses have been proposed to explain the association between cachexia and poorer prognosis. Some authors have suggested that the survival advantage associated with obesity is due to the relatively large energy stores. ${ }^{(21-23)}$ Conversely, 
Weight loss in 6 months

$<5 \%$, Referece

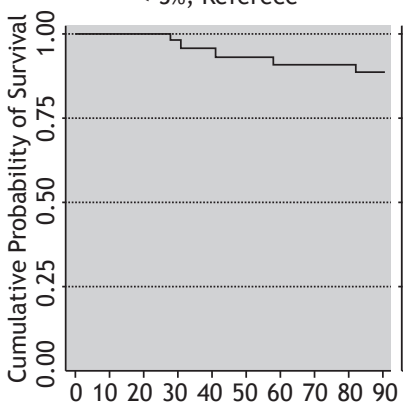

$\geq 5 \%$, P-value $=0.047$

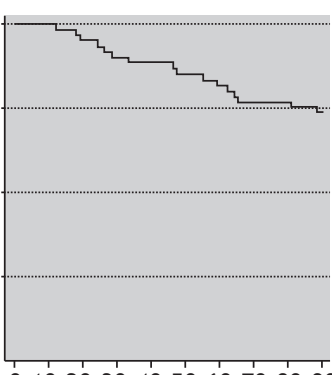

$\geq 10 \%, P$-value $=<0.001$

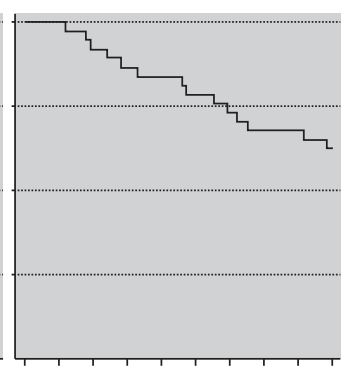

$\geq 15 \%$, P-value $=<0.001$

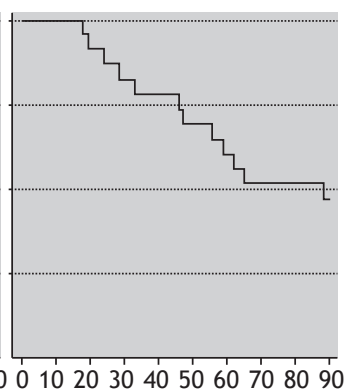

Time, days

Figure 1. Kaplan-Meier curves of cumulative survival probability, by weight loss cut-off point.

Table 3. Crude and adjusted hazard ratios for weight-loss related prognostic factors.

\begin{tabular}{lccrc}
\multicolumn{1}{c}{ Variable } & Crude HR (95\% CI) & $\mathbf{p}$ & Adjusted HR* (95\% CI) & p \\
WL, self-awareness & $2.54(0.86-7.49)$ & 0.089 & $3.59(1.03-12.48)$ & 0.044 \\
WL in 6 months $\geq 5 \%$ & $2.65(0.97-7.21)$ & 0.055 & $4.51(1.32-15.39)$ & 0.016 \\
WL in 6 months $\geq 10 \%$ & $4.45(1.80-10.99)$ & 0.001 & $6.34(2.31-17.40)$ & $<0.001$ \\
WL in 6 months $\geq 15 \%$ & $6.53(2.76-15.44)$ & $<0.001$ & $14.17(5.06-39.65)$ & $<0.001$ \\
\hline
\end{tabular}

HR: hazard ratio; and WL: weight loss. *Cox proportional hazards regression model analysis, adjusted for gender, age, Eastern Cooperative Oncology Group performance status, and tumor cell type.

when the stores are depleted, the energy balance is negative. ${ }^{(21-23)}$ Cachexia and a loss of skeletal muscle mass are associated with poor prognosis in patients with advanced NSCLC who are receiving chemotherapy. ${ }^{(10,24)}$ Another hypothesis is that individuals with sarcopenia are susceptible to infections during hospitalization and residence in nursing homes, where such infections and premature termination of treatment are both possible contributors to shortened survival. (25) Accordingly, the well-recognized poor prognosis in advanced lung cancer masks some heterogeneity that could be partially explained by WL stratification and other, as yet unconfirmed, biological factors.

Cachexia is a multifactorial syndrome with a complex pathogenesis. Therefore, multimodal interventions should be used in order to prevent WL among patients with cachexia. (26) Frequent high-calorie meals and rest before meals are recommended. Currently, there is little evidence that nutritional supplementation is efficacious. (27) Physical activity has an anti-inflammatory effect and is effective in reducing muscle catabolism, increasing protein synthesis, and reversing protein degradation. (28) Pharmacological treatment can also be used to prevent cachexia. Corticosteroids and progesterone analogs have been shown to increase appetite, thus resulting in modest weight gain. However, such drugs do not improve survival or quality of life. (29)
Our study has some limitations, not the least of which is the small sample size. In addition, there are many confounding variables that could influence the analysis of 3-month survival of patients with advanced NSCLC. One such variable is the main treatment adopted, which, in our sample. was quite heterogeneous, therefore potentially affecting the prognosis. However, we believe that using a Cox proportional hazards regression model was an effective strategy to reduce the influence of those confounders, and the associations detected retained their significance even after the multivariate analyses. Studies including larger patient samples are needed in order to corroborate our findings. Further studies should also include biomarkers linked to aggressive behavior of lung cancer, such as circulating tumor cells and circulating cell-free nucleic acids, which could also affect survival rates, and patients who have such biomarkers might show different rates of WL. ${ }^{(30)}$

Although increased efforts have been directed toward the identification of biological markers as prognostic indicators of lung cancer, there are some important clinical indices that should be also considered more thoroughly. In conclusion, our results indicate that proportional $\mathrm{WL}$ is an important prognostic factor for 3-month survival after diagnosis in patients with stage IV NSCLC.

\section{REFERENCES}

1. Ross PJ, Ashley S, Norton A, Priest K, Waters JS, Eisen T, et al. Do patients with weight loss have a worse outcome when undergoing chemotherapy for lung cancers? Br J Cancer. 2004;90(10):1905-11. https://doi.org/10.1038/sj.bjc.6601781

2. Jeremić $B$, Miličić $B$, Milisavljevic $S$. Clinical prognostic factors in patients with locally advanced (stage III) non-small cell lung cancer treated with hyperfractionated radiation therapy with and without concurrent chemotherapy: single-Institution Experience in 600 Patients. Cancer. 2011;117(13):2995-3003. https://doi.org/10.1002/ cncr.25910 
3. Martin L, Birdsell L, Macdonald N, Reiman T, Clandinin MT, McCargar $L J$, et al. Cancer cachexia in the age of obesity: skeletal muscle depletion is a powerful prognostic factor, independent of body mass index. J Clin Oncol. 2013;31(12):1539-47. https://doi.org/10.1200/ JCO.2012.45.2722

4. Fredrix EW, Wouters EF, Soeters PB, van der Aalst AC, Kester $A D$, von Meyenfeldt MF, et al. Resting energy expenditure in patients with non-small cell lung cancer. Cancer. 1991;68(7):161621. https://doi.org/10.1002/1097-0142(19911001)68:7<1616::AIDCNCR2820680725>3.0.CO;2-3

5. Hyltander A, Drott C, Körner U, Sandström R, Lundholm K. Elevated energy expenditure in cancer patients with solid tumours. Eur J Cancer. 1991;27(1):9-15. https://doi.org/10.1016/02775379(91)90050-N

6. Staal-van den Brekel A, Schols A, ten Velde G, Buurman WA Wouters EF. Analysis of energy balance in lung cancer patients. Cancer Res. 1994;54(24):6430-3.

7. Staal-van den Brekel A, Dentener MA, Schols AM, Buurman WA Wouters EF. Increased resting energy expenditure and weight loss are related to a systemic inflammatory response in lung cancer patients. J Clin Oncol. 1995;13(10):2600-5. https://doi.org/10.1200/ JC0.1995.13.10.2600

8. Melville S, McNurlan MA, Calder AG, Garlick PJ. Increased protein turnover despite normal energy metabolism and responses to feeding in patients with lung cancer. Cancer Res. 1990;50(4):112531

9. Jatoi $A$, Daly BD, Hughes $V$, Dallal GE, Roubenoff R. The prognostic effect of increased energy expenditure prior to treatment for lung cancer. Lung Cancer. 1999;23(2):153-8. https://doi.org/10.1016/ S0169-5002(99)00008-2

10. Buccheri G, Ferrigno D. Importance of weight loss definition in the prognostic evaluation of non-small-cell lung cancer. Lung Cancer. 2001;34(3):433-40. https://doi.org/10.1016/S0169-5002(01)00273-2

11. Tartari RF, Ulbrich-Kulczynski JM, Filho AF. Measurement of midarm muscle circumference and prognosis in stage IV non-small cell lung cancer patients. Oncol Lett. 2013;5(3):1063-1067. https://doi. org/10.3892/ol.2013.1128

12. Kimura M, Naito T, Kenmotsu H, Taira T, Wakuda K, Oyakawa T, et al Prognostic impact of cancer cachexia in patients with advanced nonsmall cell lung cancer. Support Care Cancer. 2015;23(6):1699-708. https://doi.org/10.1007/s00520-014-2534-3

13. Fearon K, Strasser F, Anker SD, Bosaeus I, Bruera E, Fainsinger $R L$, et al. Definition and classification of cancer cachexia: an international consensus. Lancet Oncol. 2011;12(5):489-95. https:// doi.org/10.1016/S1470-2045(10)70218-7

14. Aapro M, Arends J, Bozzetti F, Fearon K, Grunberg SM, Herrstedt $J$, et al. (2014) Early recognition of malnutrition and cachexia in the cancer patient: a position paper of a European School of Oncology Task Force. Ann Oncol. 2014;25(8):1492-9. https://doi.org/10.1093/ annonc/mdu085

15. Goldstraw P, Crowley J, Chansky K, Giroux DJ, Groome PA, RamiPorta R, et al. The IASLC Lung Cancer Staging Project: proposals for the revision of the TNM stage groupings in the forthcoming (seventh) edition of the TNM Classification of malignant tumours. J Thorac Oncol. 2007;2(8):706-14. Erratum in: J Thorac Oncol. 2007;2(10):985. https://doi.org/10.1097/JTO.0b013e31812f3c1a

16. Oken MM, Creech RH, Tormey DC, Horton J, Davis TE, McFadden
ET, et al. Toxicity and response criteria of the Eastern Cooperative Oncology Group. Am J Clin Oncol. 1982;5(6):649-55. https://doi. org/10.1097/00000421-198212000-00014

17. Centers for Disease Control and Prevention-CDC [homepage in the internet]. Atlanta (GA): CDC; [updated 2017 Jan; cited 2017 Ju 29]. National Health and Nutrition Examination Survey (NHANES)Anthropometry Procedures Manual. [Adobe Acrobat document, 102p.]. Available from: http://www.cdc.gov/nchs/data/nhanes/ nhanes_07_08/manual_an.pdf

18. Altman DG. Practical statistics for medical research, 1st ed. London: Chapman \& Hall; 1991

19. Cox DR. Regression models and life-tables. J Royal Statistical Soc Series B (Methodological) 1972;34:187-220.

20. Buccheri G, Ferrigno D, Tamburini M. Karnofsky and ECOG performance status scoring in lung cancer: a prospective, longitudina study of 536 patients from a single institution. Eur $\mathrm{J}$ Cancer 1996:32A(7):1135-41. https://doi.org/10.1016/0959-8049(95)00664-8

21. Paralkar VR, LiT, Langer CJ. Population characteristics and prognostic factors in metastatic non-small-cell lung cancer: a Fox Chase Cance Center retrospective. Clin Lung Cancer. 2008;9(2):116-21. https://doi. org/10.3816/CLC.2008.n.018

22. Blanchon F, Grivaux M, Asselain B, Lebas FX, Orlando JP, Pique $J$, et al. 4-year mortality in patients with non-small-cell lung cancer: development and validation of a prognostic index. Lancet Oncol. 2006;7(10):829-36. https://doi.org/10.1016/S1470-2045(06)70868-3

23. van der Meij BS, Schoonbeek CP, Smit EF, Muscaritoli M, van Leeuwen PA, Langius JA. Pre-cachexia and cachexia at diagnosis of stage III non-small-cell lung carcinoma: an exploratory study comparing two consensus-based frameworks. Br J Nutr 2013;109(12):2231-9. https://doi.org/10.1017/S0007114512004527

24. Goldstraw P, Ball D, Jett JR, Le Chevalier T, Lim E, Nicholson AG, et al. Non-small-cell lung cancer. Lancet. 2011;378(9804):1727-40. https://doi.org/10.1016/S0140-6736(10)62101-0

25. Kovarik M, Hronek M, Zadak Z. Clinically relevant determinants of body composition, function and nutritional status as mortality predictors in lung cancer patients. Lung Cancer. 2014;84(1):1-6 https://doi.org/10.1016/j.lungcan.2014.01.020

26. Aversa Z, Costelli P, Muscaritoli M. Cancer-induced muscle wasting latest findings in prevention and treatment. Ther Adv Med Oncol. 2017;9(5):369-382. https://doi.org/10.1177/1758834017698643

27. Koretz RL, Lipman TO, Klein S; American Gastroenterological Association. AGA technical review on parenteral nutrition Gastroenterology. 2001;121(4):970-1001. https://doi.org/10.1053/ gast.2001.28031

28. Gould DW, Lahart I, Carmichael AR, Koutedakis Y, Metsios GS Cancer cachexia prevention via physical exercise: molecula mechanisms. J Cachexia Sarcopenia Muscle. 2013;4(2):111-24 https://doi.org/10.1007/s13539-012-0096-0

29. Ruiz Garcia V, López-Briz E, Carbonell Sanchis R, Gonzalvez Perales $\mathrm{JL}$, Bort-Marti S. Megestrol acetate for treatment of anorexia-cachexia syndrome. Cochrane Database Syst Rev. 2013;(3):CD004310. https://doi.org/10.1002/14651858.CD004310.pub3

30. Matikas A, Syrigos KN, Agelaki S. Circulating Biomarkers in NonSmall-Cell Lung Cancer: Current Status and Future Challenges. Clin Lung Cancer. 2016;17(6):507-516. https://doi.org/10.1016/j. cllc.2016.05.021 